\title{
Получение и исследование пористой структуры минерально-углеродных адсорбентов на основе силикагеля и полимерных отходов
}

\author{
Нистратов А.В., Скарюкин А.С., Клушин В.Н. \\ ФГБОУ ВО «Российский химико-технологический университет им. Д.И. Менделеева», Москва
}

Поступила в редакцию 8.05.2018 г.

DOI: https://doi.org/10.17308/sorpchrom.2019.19/739

Описан способ получения и охарактеризована пористая структура минерально-углеродных адсорбентов на основе двух видов силикагеля и отходов полиэтилена, полипропилена и полиуретана. Представлены изотермы низкотемпературной адсорбции ими азота, по которым рассчитаны размеры, удельный объём и поверхность микро- и мезопор. Показано, что при пиролизе указанных полимеров мезопористая структура адсорбентов меняется незначительно, а микропористая структура сохраняется только с крупнопористым силикагелем, являющимся более подходящей минеральной основой.

Ключевые слова: минерально-углеродные адсорбенты, силикагель, полимерные отходы, пористая структура.

\section{Production and investigation of porous structure of mineral-carbon adsorbents based on silica-gel and polymer wastes}

\author{
Nistratov A.V., Skaryukin A.S., Klushin V.N. \\ Mendeleev University of Chemical Technology of Russia, Moscow
}

The work is devoted to investigation of porous structure of adsorbents, obtained from silica gels KSM and KSK and waste polyethylene, polypropylene and polyurethane by the method of chemical vapor deposition. This direction of treatment provides production of composite porous materials from thermoplastic polymers, completely decomposing during pyrolysis. Electron microscopy of the adsorbents reveals uneven deposition of pyrolysis carbon on the surface of silica gel in form of globules. The pore parameters of carbonized silica gels and were measured by low-temperature adsorption-desorption of nitrogen using the theories of BET, BJH, Dubinin-Astakhov and estimated by the method of molecular probes (water, benzene, tetrachlormethane). The obtained mineral-carbon adsorbents based on wide-porous silica gel refer to mesoporous materials, adsorbents based on narrow-porous silica gel are mostly microporous (the total pore volume up to 0.97 and $0.52 \mathrm{~cm}^{3} / \mathrm{g}$, respectively). Pore shrinkage of silica gels due to coating with a layer of carbon during the pyrolysis of polymers is found: for wide-porous silica gel it changes their porous structure insignificantly (specific surface $333-321 \mathrm{~m}^{2} / \mathrm{g}$ ), for narrow-porous - to partial blocking of micropores and to decreasing of their parameters (fall of specific surface from 712 to $378 \mathrm{~m}^{2} / \mathrm{g}$ ). The similarity of adsorption-desorption isotherms and pore distribution curves of the samples indicate a weak effect of the type of pyrolyzed polymer, pyrolysis regime for wide-porous silica gel, and the ratio of polymer to narrow-porous silica gel on the adsorbent parameters (average pore size 11.4-11.6 nm and 2.74-2.95 nm, respectively).Wide-porous silica gel KSK as a more heat-resistant and porous material is the best matrix for production of mineral-carbon adsorbents. The obtained granulated adsorbents qualitatively exceed the industrial activated carbons, and the described method of their synthesis contributes to utilization of the widespread polymer waste.

Keywords: mineral-carbon adsorbents, silica gel, polymeric waste, porous structure 


\section{Введение}

Утилизация твёрдых коммунальных отходов вообще и отходов синтетических полимеров в частности становится стратегической государственной задачей [1]. Объём образования полимерных отходов в России по разным оценкам составляет 700-900 тыс. т в год, причём в их составе преобладают упаковочные материалы из полиэтилена (ПЭ, 34\%), полиэтилентерефталата (ПЭТФ, 20\%) и полипропилена (ПП, $14 \%)$. Непрерывно возрастающее применение в современной теплоизоляции зданий и оборудования полиуретана и его негорючей разновидности - полиизоцианурата (ПИР) усугубляет проблему утилизации отходов названных полимеров.

Возможность термической утилизации органических отходов обеспечивает метод ГФХО - пиролиз полимера, сопровождающийся «газофазным физикохимическим осаждением» и карбонизацией его продуктов (пиролитического углерода) на пористых минеральных носителях - силикагелях, глинах, цеолитах [2].

В источниках [3-5] описаны получение и свойства пористых материалов на основе силикагеля (карбосилов), где источником пироуглерода служат легко разлагаемые соединения, например, дихлорметан. Авторы отмечают, что получаемые продукты обладают сочетанием свойств углеродных и минеральных адсорбентов. Однако углеродный компонент могут вносить и отходы, например, пропитанный нефтью бентонит [6] и отработанная смола [7].

Применительно к полиуретановым отходам сходный процесс, названный «гетерогенным вторичным пиролизом» [8], исследован в присутствии активного угля и твёрдого остатка пиролиза самого полиуретана. Результатом явились изменение состава жидких продуктов пиролиза и образование дополнительного количества углерода на поверхности носителей. Наряду с этим авторы [9] рассматривают твёрдые продукты подобного превращения отходов полиуретана в присутствии силикагеля как композиционные адсорбенты.

Перечисленные полимерные материалы (кроме ПИР) относятся к термопластичным, не образующим твёрдого остатка при полном термическом разложении. Поэтому получение углеродсодержащих адсорбентов путём пиролиза указанных отходов в присутствии пористого минерального носителя, способное повысить рентабельность их утилизации, представляется перспективным. Оценка их качества и перспектив применения требует исследования пористой структуры таких материалов, которое и явилось целью настоящей работы.

\section{Эксперимент}

Согласно описанному выше методу совместного пиролиза [9] источниками пироуглерода служили типовые полимерные отходы: прозрачные ПЭ пакеты, фрагменты ПП посуды размером до 1 см, крошка сэндвич-панелей из ПИР до 0.5 мм. В качестве носителя выбраны крупные (3-5 мм) гранулированные силикагели - крупнопористый (КСК) и мелкопористый (КСМ). Предпочтение силикагеля в роли матрицы (носителя) для нанесения пироуглерода обусловлено его свойствами [10]. Он относится к мезопористым адсорбентам (преимущественный радиус пор от 2 до 50 нм в зависимости от структуры), для него характерны высокая удельная поверхность (до $\left.800 \mathrm{~m}^{2} / \Gamma\right)$ и суммарный объём пор (0.3-1.2 см $3 /$ ), сравнительная термостойкость: мелкопористый силикагель - до 500, крупнопористый - до $900^{\circ} \mathrm{C}$.

Образцы минерально-углеродных адсорбентов (МУА) на их основе получали, помещая предварительно высушенный носитель в трубчатый реактор над слоем фрагментов полимера, соблюдая массовое отношение полимер : силикагель равным 
$1: 0.5$ и $1 ; 2$ и проводя пиролиз (нагревание со скоростью 5 или $10{ }^{\circ} \mathrm{C} / \mathrm{Mин)} \mathrm{до} \mathrm{400-}$ 700 (ПЭ и ПП) или $800{ }^{\circ} \mathrm{C}$ (ПИР) с последующей изотермической выдержкой в течение часа. При этом МУА формировались путём отложения пироуглерода на гранулах силикагеля в атмосфере продуктов разложения полимерных отходов. Количество осаждённого пироуглерода оценивали по изменению массы загрузки силикагеля после пиролиза, визуально констатируемому наличием углерода во всём объёме и на поверхности гранул силикагеля. При использовании ПЭ и ПП в отношении полимер : силикагель КСК = $1: 0.5$ изменение массы практически отсутствует (дегидратация силикагеля и осаждение пироуглерода взаимно компенсируются), при разложении ПИР имеет место потеря 6-11\% массы целевого продукта относительно исходного силикагеля КСМ (дегидратация преобладает).

Пористая структура полученных минерально-углеродных адсорбентов исследована стандартным методом низкотемпературной адсорбции-десорбции ими азота (температура $-196{ }^{\circ} \mathrm{C}$, интервал относительного давления газа 0.005-0.995). Предподготовка образцов заключалась в их дегазировании при $300^{\circ} \mathrm{C}$ под вакуумом в атмосфере азота (остаточное давление 0.5 мм рт. ст.) в течение 12 ч. Измерения выполнены на автоматическом анализаторе ASAP 2020 (Micromeritics, CША) Центра коллективного пользования РХТУ им. Д.И. Менделеева, позволяющем получать изотермы его адсорбции и десорбции, проводить расчёты площади поверхности по методу БЭТ - Брунауэра-Эммета-Теллера (удельная поверхность $S_{\text {уд }}$ ), распределения мезопор по меторду БДХ - Баррета-Джойнера-Халенды (объём $\mathrm{V}^{\mathrm{S}}$ сорбирующих пор с размерами 1.7-300 нм) и характеристик микропор по методу ДА - ДубининаАстахова [11].

Для оценки качества полученных адсорбентов суммарный объём их пор определён кипячением в воде согласно [12]. Объёмы сорбирующих пор (микро- и мезопор), характеризующие способность к поглощению водяного пара и паров растворителей, измерены в статических условиях: предварительно высушенные при $110^{\circ} \mathrm{C}$ и взвешенные до 0.0001 г образцы помещали в эксикаторы с насыщенными парами воды, бензола и тетрахлорметана, выдерживали 7 суток $\left(20 \pm 2^{\circ} \mathrm{C}\right)$ и взвешиванием определяли массу поглощённых веществ, переводя её в объём через плотность соответствующих жидкостей.

Электронные снимки поверхности полученных продуктов на основе отходов ПЭ и ПП выполнены методом сканирующей электронной микроскопии также на оборудовании Центра коллективного пользования РХТУ им. Д.И. Менделеева (микроскоп JEOL, 1000-кратное увеличение).

\section{Обсуждение результатов}

На фотографиях всех образцов (рис. 1) видны точечные образования пироуглерода (т.н. глобулы) размером до 1 мкм на поверхности силикагеля. Нагрев компонентов с интенсивностью $10^{\circ} \mathrm{C} /$ мин способствует осаждению пироуглерода по сравнению с медленным нагревом. При $700^{\circ} \mathrm{C}$ процесс более результативен: пиролиз протекает полнее, размер глобул уменьшается, и распределение в покрытии становится более однородным. Расчётная толщина слоя пироуглерода массой $4 \%$ от силикагеля с удельной поверхностью $250 \mathrm{~m}^{2} / \Gamma$ (в предположении его равномерного нанесения и аморфной структуры с плотностью технического углерода 1.8 г/см ${ }^{3}$ ) составляет 0.09 нм.

Изотермы адсорбции и десорбции азота $\left(-196^{\circ} \mathrm{C}\right.$, интервал относительного давления 0.01-0.995) образцами на основе полиэтилена и полипропилена представлены на рис. 2, графики распределения их пор по размеру - на рис. 3. Изотермы для 
композиционных адсорбентов на основе упаковочных полимеров относятся к IV типу по классификации Брунауэра-Деминга-Деминга-Теллера [11]. Начальный участок на них при относительном давлении до 0.1 соответствует заполнению микропор, а основной прирост адсорбционной ёмкости в области $\mathrm{P} / \mathrm{Ps}=0.1-0.995$ обусловлен заполнением мезопор, что подтверждается выраженным гистерезисом ветвей адсорбции и десорбции. Форма изотерм практически не зависит от условий получения МУА и вида полимера-источника пироуглерода.

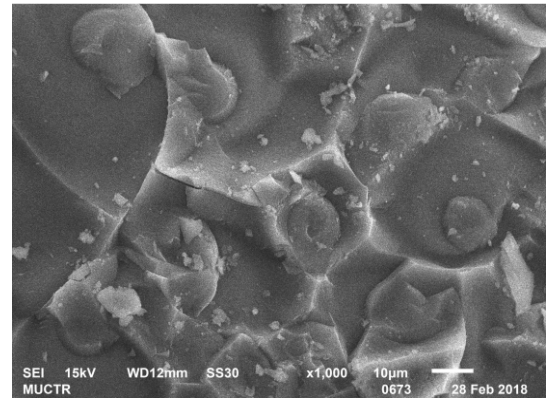

a

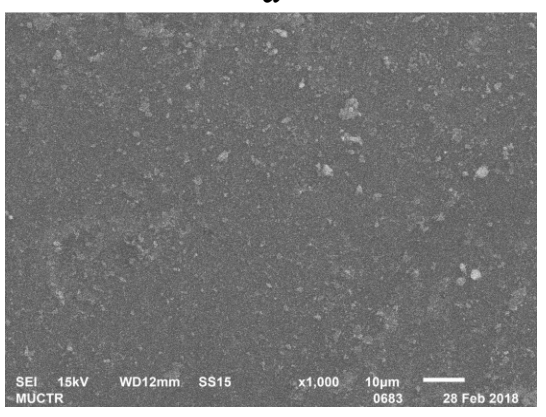

B

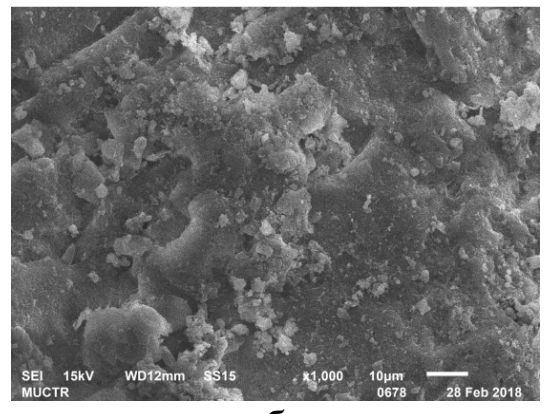

6

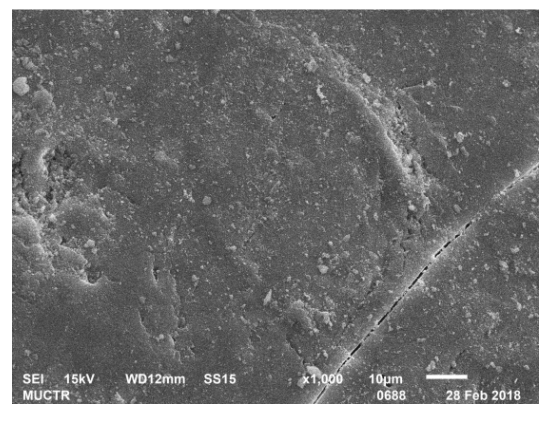

$\Gamma$

Рис. 1. Снимки СЭМ адсорбентов на основе силикагеля КСК:

$\mathrm{a}-\Pi$ Э $\left(5^{\circ} \mathrm{C} / \mathrm{мин,} 400^{\circ} \mathrm{C}\right) ; \sigma-\Pi \ni\left(10^{\circ} \mathrm{C} / \mathrm{мин,} 400 \mathrm{C}\right) ;$ в - ПЭ $\left(10^{\circ} \mathrm{C} / \mathrm{мин,} 700^{\circ} \mathrm{C}\right)$; г - ПП $\left(10^{\circ} \mathrm{C} / \mathrm{мин,} 700^{\circ} \mathrm{C}\right)$. Кратность увеличения х1000.

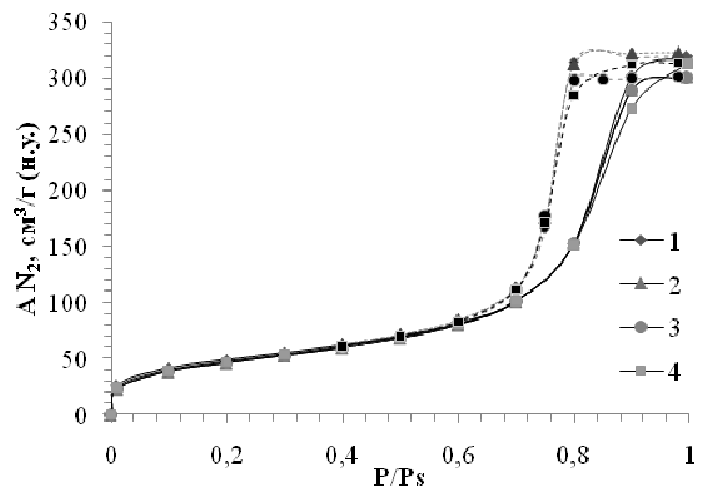

Рис. 2. Изотермы адсорбции и десорбции азота на адсорбентах на основе силикагеля КСК: 1 - ПЭ $\left(5^{\circ} \mathrm{C} / \mathrm{мин,}\right.$ $\left.400^{\circ} \mathrm{C}\right) ; 2-\Pi$ - $\left(10^{\circ} \mathrm{C} / \mathrm{мин,} 400^{\circ} \mathrm{C}\right)$; 3 - ПЭ $\left(10^{\circ} \mathrm{C} / \mathrm{мин,} 700^{\circ} \mathrm{C}\right)$; $4-\Pi$ - $\left(10^{\circ} \mathrm{C} / \mathrm{мин,} 700^{\circ} \mathrm{C}\right)$

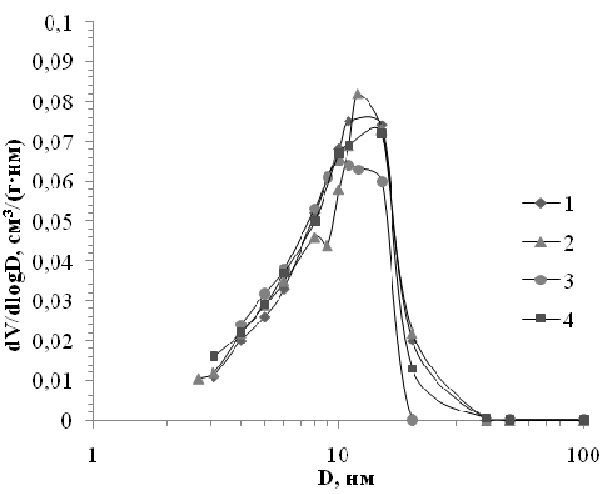

Рис. 3. Дифференциальное распределение пор по диаметру (по методу

БДХ) адсорбентов на основе силикагеля КСК: 1 - ПЭ $\left(5^{\circ} \mathrm{C} / \mathrm{мин,} 400^{\circ} \mathrm{C}\right)$;

2 - ПЭ $\left(10^{\circ} \mathrm{C} / \mathrm{мин,} 400^{\circ} \mathrm{C}\right)$; 3 - ПЭ $\left(10^{\circ} \mathrm{C} / \mathrm{мин,} 700^{\circ} \mathrm{C}\right) ; 4-\Pi \Pi$ $\left(10^{\circ} \mathrm{C} /\right.$ мин, $\left.700{ }^{\circ} \mathrm{C}\right)$

Кривые распределения мезопор полученных адсорбентов по диаметру (рис. 3) имеют один максимум (11-15 нм), характеризуются сравнительно узким диапазоном 
размеров мезопор: 3-20 нм. Средний диаметр пор силикагеля КСК составляет 11.2 нм, следовательно, видимые отложения пироуглерода на поверхности практически не меняют пористую структуру носителя.

Рассчитанные по названным методам показатели пористой структуры МУА на основе силикагеля КСК в сочетании с ПЭ, ПП отходами представлены в табл. 1-2. Анализ показателей пористой структуры адсорбентов на основе отходов ПЭ и ПП указывает на преобладание в них мезопор (96-98 \% суммарного объёма пор), присущее исходному крупнопористому силикагелю. Их удельные объём и поверхность незначительно уступают таковым силикагеля КСК. Более точная оценка объёма микропор по методу Дубинина-Астахова выявляет их объём до $0.185 \mathrm{~cm}^{3} / \Gamma$, характерный для носителя, причём они вносят наибольший вклад в удельную поверхность адсорбентов.

Таблица 1. Характеристики пористой структуры минерально-углеродных адсорбентов на основе силикагеля КСК и отходов ПЭ и ПП (по методам БЭТ и БДХ)

\begin{tabular}{|c|c|c|c|c|}
\hline \multirow{2}{*}{ Образец } & \multicolumn{2}{|c|}{ Объём пор, см³/Г (БДХ) } & \multirow{2}{*}{$\begin{array}{c}\text { Средняя ши- } \\
\text { рина пор, нм } \\
\text { (БЭТ) }\end{array}$} & \multirow{2}{*}{$\begin{array}{c}\text { Удельная по- } \\
\text { верхность } \mathrm{S}_{\mathrm{yд}}, \\
\mathrm{m}^{2} / \Gamma \\
(\text { БЭТ) }\end{array}$} \\
\hline & $\begin{array}{l}\text { сорбиру- } \\
\text { ющих V }\end{array}$ & мезопор $\mathrm{V}_{\text {ме }}$ & & \\
\hline КСК & 1.02 & 1.02 & 11.2 & 333 \\
\hline ПЭ + КСК $\left(5^{\circ} \mathrm{C} / \mathrm{мин,}, 400^{\circ} \mathrm{C}\right)$ & 0.931 & 0.927 & 11.4 & 321 \\
\hline ПЭ + КСК $\left(10^{\circ} \mathrm{C} / \mathrm{мин,}, 400^{\circ} \mathrm{C}\right)$ & 0.941 & 0.940 & 11.6 & 320 \\
\hline$\Pi Э+$ КСК $\left(10^{\circ} \mathrm{C} / \mathrm{мин,}, 700^{\circ} \mathrm{C}\right)$ & 0.847 & 0.847 & 11.0 & 314 \\
\hline ПП+ КСК $\left(10^{\circ} \mathrm{C} / \mathrm{мин,}, 700^{\circ} \mathrm{C}\right)$ & 0.914 & 0.876 & 11.5 & 314 \\
\hline
\end{tabular}

Таблица 2. Характеристики микропористой структуры минерально-углеродных адсорбентов на основе силикагеля КСК и отходов ПЭ и ПП (по методу ДА)

\begin{tabular}{|c|c|c|c|c|c|}
\hline Образец & $\begin{array}{l}\text { Предель- } \\
\text { ный объ- } \\
\text { ём мик- } \\
\text { ропор } \\
\mathrm{W}_{0}, \mathrm{~cm}^{3} / \Gamma\end{array}$ & $\begin{array}{c}\text { Удельная } \\
\text { поверх- } \\
\text { ность } \\
\text { микропор } \\
\mathrm{S}_{\text {ми }}, \mathrm{M}^{2} / \Gamma\end{array}$ & $\begin{array}{c}\text { Средняя } \\
\text { эквива- } \\
\text { лентная } \\
\text { ширина } \\
\text { пор } \\
\mathrm{B}_{0}, \mathrm{Hм} \\
\end{array}$ & $\begin{array}{c}\text { Характеристиче- } \\
\text { ская энергия ад- } \\
\text { сорбции } \mathrm{E}_{\mathrm{A}}, \\
\text { кДж/моль }\end{array}$ & $\begin{array}{c}\text { Коэффици- } \\
\text { ент корре- } \\
\text { ляции }\end{array}$ \\
\hline КСК & 0.192 & 356 & 2.16 & 9.96 & 0.9999 \\
\hline ПЭ + КСК $\left(5^{\circ} \mathrm{C} / \mathrm{мин,}, 400^{\circ} \mathrm{C}\right)$ & 0.185 & 345 & 2.14 & 10.2 & 0.9999 \\
\hline ПЭ + КСК $\left(10^{\circ} \mathrm{C} / \mathrm{мин,} 400^{\circ} \mathrm{C}\right)$ & 0.185 & 341 & 2.16 & 9.93 & 0.9999 \\
\hline ПЭ + КСК $\left(10^{\circ} \mathrm{C} / \mathrm{мин,}, 700^{\circ} \mathrm{C}\right)$ & 0.18 & 323 & 2.23 & 9.09 & 0.9999 \\
\hline ПП+ КСК $\left(10^{\circ} \mathrm{C} / \mathrm{мин}, 700^{\circ} \mathrm{C}\right)$ & 0.182 & 330 & 2.21 & 9.38 & 0.9999 \\
\hline
\end{tabular}

Как следует из табл. 1 и 2, варьирование полимеров и температурного режима пиролиза не позволяет улучшить показатели адсорбентов. Тем не менее объём их микро- и мезопор сопоставим с таковым исходного КСК и превосходит показатели промышленных активных углей, например, ФАС-3 с суммарным объёмом пор 0.640.78, объёмом микропор 0.33-0.4 и мезопор 0.3-0.36 $\mathrm{cm}^{3} / \Gamma$ [3, с. 11].

Результаты аналогичного изучения пористой структуры адсорбентов на основе силикагеля КСМ и полиуретанового отхода отражены на рис. 4 и 5. Полученные для данных адсорбентов изотермы также принадлежат к IV типу, характерному для мезопористых материалов. Такая структура проявляется и в выраженном гистерезисе в области относительного давления азота 0.4-0.7. Соответствующие кривые распределения пор по размерам (рис. 5) выявляют мономодальную пористую структуру с максимумом при диаметре 2.6-2.8 нм (для КСМ средний размер пор 3.97 нм); поры 
с диаметром более 10 нм практически не представлены. Формы кривых как рис. 4, так и рис. 5 мало зависят от отношения ПИР : КСМ, несмотря на различие массы отложений пироуглерода.

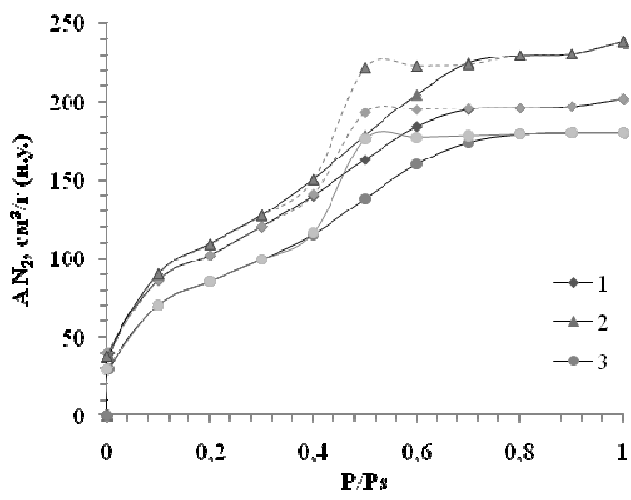

Рис. 4. Изотермы адсорбции и десорбции азота на адсорбентах с различным отношением отходов ПИР и силикагеля КСМ: $1-1: 0,5 ; 2-1: 1 ; 3-1$ : 2

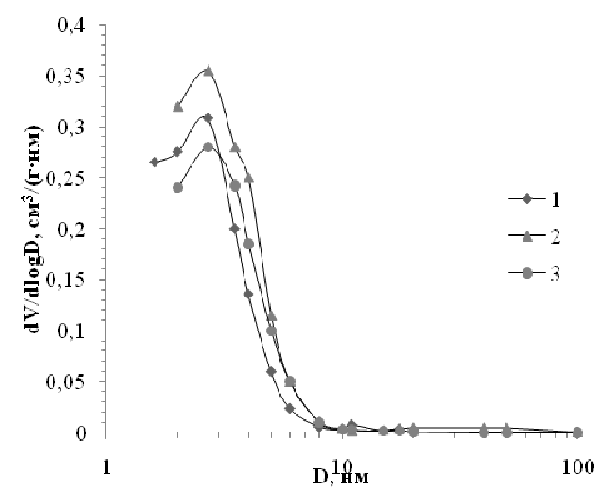

Рис. 5. Дифференциальное распределение пор по диаметру (по методу БДХ) адсорбентов с различным отношением отходов ПИР и силикагеля КСМ: $1-1: 0,5 ; 2-1: 1 ; 3-1: 2$

Рассчитанные по названным методам показатели пористой структуры МУА на основе КСМ и ПИР представлены в табл. 3 и 4. Анализ данных табл. 3 свидетельствует, что у полученных материалов заметно сокращается объём макропор, а объёмы микро- и мезопор близки. Следует отметить, что повышение отношения носителя и отхода до $1: 1$ обеспечивает прирост объёма мезопор на $30 \%$ относительно исходного силикагеля. Таким образом, наблюдаемые явления связаны с деградацией пористой структуры КСМ при нагревании и осаждением продуктов пиролиза ПИР, сужающим поры носителя.

Таблица 3. Характеристики пористой структуры минерально-углеродных адсорбентов на основе силикагеля КСМ и отходов ПИР (по методам БЭТ и БДХ)

\begin{tabular}{|c|c|c|c|c|}
\hline \multirow[b]{2}{*}{$\begin{array}{c}\text { Образец } \\
\text { ПИР : КСМ }\end{array}$} & \multicolumn{2}{|c|}{ Объём пор, $\mathrm{cm}^{3} / \Gamma$ (БДХ) } & \multirow{2}{*}{$\begin{array}{l}\text { Средний диа- } \\
\text { метр пор, нм } \\
\text { (БДХ) }\end{array}$} & \multirow{2}{*}{$\begin{array}{c}\text { Удельная поверх- } \\
\text { ность } \mathrm{S}_{\text {уд }}, \mathrm{M}^{2} / \Gamma \\
\text { (БЭТ) }\end{array}$} \\
\hline & $\begin{array}{c}\text { сорбирующих } \mathrm{V}^{\mathrm{S}} \\
(1.7-300 \mathrm{Hм})\end{array}$ & мезопор $\mathrm{V}_{\text {ме }}$ & & \\
\hline КСM & 0.1 & 0.1 & 3.97 & 712 \\
\hline $1: 0.5$ & 0.107 & 0.094 & 2.74 & 378 \\
\hline $1: 1$ & 0.145 & 0.13 & 2.95 & 401 \\
\hline $1: 2$ & 0.115 & 0.103 & 2.90 & 311 \\
\hline
\end{tabular}

Таблица 4. Характеристики микропористой структуры минерально-углеродных адсорбентов на основе силикагеля КСМ и отходов ПИР (по методу ДА)

\begin{tabular}{|c|c|c|c|c|c|}
\hline $\begin{array}{c}\text { Образец } \\
\text { ПИР : КСМ }\end{array}$ & $\begin{array}{c}\text { Предельный } \\
\text { объём микро- } \\
\text { пор } \mathrm{W}_{0}, \mathrm{~cm}^{3} / \Gamma\end{array}$ & $\begin{array}{c}\text { Удельная по- } \\
\text { верхность } \\
\text { микропор } \mathrm{S}_{\text {ми }} \\
\mathrm{m}^{2} / \Gamma\end{array}$ & $\begin{array}{c}\text { Средняя эк- } \\
\text { вивалент-ная } \\
\text { ширина пор } \\
\mathrm{B}_{0}, \text { нм }\end{array}$ & $\begin{array}{c}\text { Характеристи- } \\
\text { ческая энергия } \\
\text { адсорбции } \mathrm{E}_{\mathrm{A}}, \\
\text { кДж/моль }\end{array}$ & $\begin{array}{c}\text { Коэффициент } \\
\text { корреляции }\end{array}$ \\
\hline КСМ & 0.388 & 753 & 2.06 & 11.5 & 0.9999 \\
\hline $1: 0.5$ & 0.187 & 366 & 2.04 & 11.7 & 0.99996 \\
\hline $1: 1$ & 0.19 & 370 & 2.05 & 11.5 & 0.99999 \\
\hline $1: 2$ & 0.143 & 282 & 2.02 & 11.8 & 0.9999 \\
\hline
\end{tabular}

Объёмы мезопор образцов на основе КСК на порядок больше таковых образ- 
цов на основе КСМ, что делает первый из этих носителей более подходящим для создания композиционных адсорбентов данным способом.

Согласно методу Дубинина-Астахова (табл. 4) микропористая структура образцов выявляет аналогичные данным табл. 3 закономерности её формирования. Как и для образцов на основе КСК, средние размеры микропор и энергия адсорбции в них практически одинаковы.

Весовой метод определения сорбирующих пор (табл. 5) даёт представление о возможностях адсорбентов поглощать воду, бензол и тетрахлорметан из паровоздушных смесей при $\mathrm{P} / \mathrm{Ps}=1$. Сравнение пористой структуры полученных адсорбентов на основе КСК с таковой исходного силикагеля выявляет снижение суммарного объёма пор на 10\%, объёмы сорбирующих пор по бензолу и тетрахлорметану (микро- и мезопор) меняются незначительно, но замечено развитие новых субмикропор (возрастает объём пор, сорбирующих воду), вероятно, обусловленное сужением существующих. Аналогичные показатели образцов, полученных в одинаковых условиях с использованием ПЭ и ПП, близки за исключением объёма сорбирующих пор по воде. Уменьшение скорости нагрева и подъём температуры пиролиза, как это демонстрируют образцы на основе ПЭ, неблагоприятны, т.к. способствуют заполнению сорбирующих пор углеродом и приводят к некоторому сокращению их объёмов.

Таблица 5. Показатели пористой структуры минерально-углеродных адсорбентов

\begin{tabular}{|c|c|c|c|c|c|}
\hline \multirow{2}{*}{ Сырьё и условия пиролиза } & \multirow{2}{*}{$\begin{array}{l}\text { Отношение } \\
\text { полимер : } \\
\text { силикагель }\end{array}$} & \multirow{2}{*}{$\begin{array}{c}\text { Суммарный } \\
\text { объём пор, } \\
\text { см }^{3} / \Gamma\end{array}$} & \multicolumn{3}{|c|}{$\begin{array}{c}\text { Объём сорбирующих пор } \\
\left(\mathrm{cm}^{3} / \Gamma\right) \text { по парам }\end{array}$} \\
\hline & & & $\mathrm{C}_{6} \mathrm{H}_{6}$ & $\mathrm{CCl}_{4}$ & $\mathrm{H}_{2} \mathrm{O}$ \\
\hline КСК & - & 1.09 & 0.95 & 0.93 & 0.48 \\
\hline ПЭ + КСК $\left(5^{\circ} \mathrm{C} /\right.$ мин, $\left.400^{\circ} \mathrm{C}\right)$ & \multirow{4}{*}{$1: 0.5$} & 0.97 & 0.83 & 0.90 & 0.58 \\
\hline$\Pi Э+$ КСК $\left(10^{\circ} \mathrm{C} / \mathrm{мин,}, 400^{\circ} \mathrm{C}\right)$ & & 0.97 & 0.94 & 0.97 & 0.58 \\
\hline ПЭ + КСК $\left(10^{\circ} \mathrm{C} / \mathrm{мин}, 700^{\circ} \mathrm{C}\right)$ & & 0.92 & 0.92 & 0.91 & 0.51 \\
\hline ПП+ КСК $\left(10^{\circ} \mathrm{C} /\right.$ мин, $\left.700^{\circ} \mathrm{C}\right)$ & & 0.91 & 0.91 & 0.89 & 0.76 \\
\hline KCM & - & 0.95 & 0.83 & 0.82 & 0.25 \\
\hline ПИР+ КСМ $\left(10^{\circ} \mathrm{C} / \mathrm{мин}, 800^{\circ} \mathrm{C}\right)$ & $1: 0.5$ & 0.44 & 0.11 & 0.26 & 0.25 \\
\hline ПИР+ КСМ $\left(10^{\circ} \mathrm{C} / \mathrm{мин}, 800^{\circ} \mathrm{C}\right)$ & $1: 1$ & 0.42 & 0.29 & 0.31 & 0.33 \\
\hline ПИР+ КСМ $\left(10^{\circ} \mathrm{C} / \mathrm{мин}, 800^{\circ} \mathrm{C}\right)$ & $1: 2$ & 0.52 & 0.29 & 0.09 & 0.33 \\
\hline
\end{tabular}

Суммарный объём пор образцов МУА на основе ПИР по сравнению с носителем уменьшается почти двукратно за счёт резкого сокращения объёмов микро- и мезопор, причём соотношение объёмов пор, сорбирующих растворители и воду, выравнивается. Отчасти эти изменения связаны с деградацией пористой структуры КСМ при высоких температурах [9], а также с закупоркой микропор силикагеля пироуглеродом. С увеличением массы КСМ относительно ПИР до $1: 1$ объём отложений пироуглерода на поверхности силикагеля уменьшается, что проявляется увеличением объёма всех сорбирующих пор. Объёмы пор адсорбентов на основе КСМ по растворителям сильно уступают показателям исходного носителя.

Оцененные таким способом объёмы микро- и мезопор коррелируют, хотя и не совпадают с их значениями по табл. 1-4 вследствие использования разных адсорбатов. Однако статическая ёмкость адсорбентов на основе силикагелей по бензолу выше измеренной нами для активного угля АР-А $\left(0.25\right.$ г/г, или $\left.0.28 \mathrm{~cm}^{3} / \Gamma\right)$.

Известно, что силикагели относятся к гидрофильным адсорбентам - это свойство ограничивает их применение для очистки влажных газов. Полученные композиционные адсорбенты благодаря карбонизации поверхности обладают способностью к адсорбции как паров воды, так и органических растворителей, что потенци- 
ально составляет их преимущество и оправдывает данный способ утилизации полимерных отходов.

\section{Заключение}

Использованный в работе метод позволяет получать композиционные гранулированные адсорбенты на основе силикагеля и отходов полиэтилена, полипропилена и полиуретана при их совместной термообработке в области $400-800{ }^{\circ} \mathrm{C}$ за счёт осаждения пиролитического углерода на поверхности и в порах носителя. Полученные адсорбенты относятся к преимущественно мезопористым, описываемым изотермами адсорбции азота IV типа согласно методам БЭТ и БДХ, причём параметры их мезопор близки к таковым исходных силикагелей. Термообработка и осаждение на носителях пироуглерода сопровождается сужением пор: объём и удельная поверхность микропор по методу Дубинина-Астахова для силикагеля КСМ снижаются, для КСК - сохраняются на уровне исходных. На примере силикагеля КСК в сочетании с ПЭ показано слабое влияние скорости нагрева и температуры пиролиза на пористую структуру продуктов. Варьирование соотношения ПИР : КСМ в пределах до $1: 1$ также мало меняет показатели адсорбентов по сравнению с носителем. Таким образом, совместная переработка названных полимерных отходов и термостойкого силикагеля марки КСК обеспечивает получение минерально-углеродных адсорбентов с параметрами, задаваемыми структурой носителя.

\section{Работа выполнена при финансовой поддержке РХТУ им. Д.И. Менделеева.} Номер проекта 004-2018.

\section{Список литературы}

1. Стратегия развития промышленности по обработке, утилизации и обезвреживанию отходов производства и потребления на период до 2030 года. Распоряжение Правительства РФ от 25.01.2018 № 84-Р.

2. Елецкий П.М. Дисс. к.х.н. Новосибирск: Институт катализа им. Г.К. Борескова СО PAH. 2009. 115 c.

3. Dabrowsky A., Tertykh V.A. Adsorbtion on new and modified inorganic sorbents. Amsterdam. 1996. pp. 115-146.

4. Gunko V.M., Matkovsky A.K., Charmas B. et al. // J. of Thermal Analysis and Calorimetry. 2017. Vol. 128. Issue 3. pp. 1683-1697.

5. Patent of USA US9073038B2. Carr P.W., McCormick A.V., Paek Ch. Carbon coated silica particles and methods of making same. Publ. 07.07.2015.

6. Leboda R., Charmas B., SkubiszewskaZieba J. et al. // Journal of Colloid and Interface Science. 2005. Vol. 284. Issue 1. pp. 39-47.

7. Horikawa T., Hayashi J., Muroyama K. // Carbon. 2002. Vol. 40. pp. 709-714. (Studies in Surface Science and Catalysis. Vol. 99).
8. Takamoto D.Y., Petrich M.A., Industrial \& Engineering Chemistry Research, 1994, Vol. 33, pp. 3004-3009.

9. Скарюкин А.С., Нистратов А.В., Клушин В.Н., Калинина Д.Д. // «Успехи в химии и химической технологии». Сборник материалов XIII Международного конгресса молодых учёных по химии и химической технологии. М.: Изд-во РХТУ им. Д.И. Менделеева. 2017. Т. 31. № 9. С. 47-49.

10. Алехина М.Б. Промышленные адсорбенты: учеб. пособие. М. Изд-во РХТУ им. Д.И. Менделеева. 2007. 116 с.

11. Вячеславов А.С., Ефремова М. Определение площади поверхности и пористости материалов методом сорбции газов. М. МГУ им. М.В. Ломоносова. 2011. 65 с.

12. Колышкин Д.А., Михайлова К.К. Активные угли: свойства и методы испытаний. Л. Химия. $1972.56 \mathrm{c}$ 


\section{References}

1. Strategija razvitija promyshlennosti po obrabotke, utilizacii i obezvrezhivaniju othodov proizvodstva i potreblenija na period do 2030 goda. Directive of the Government of RF at 25.01.2018 № 84-R. Available at: http://government.ru/docs/31184 (accessed 03.04.2018).

2. Eleckij P.M. Diss. cand.him. nauk. Novosibirsk: Institutkatalizaim. G.K. Boreskova SO RAN. 2009. 115 p.

3. Dabrowsky A., Tertykh V.A. Adsorbtion on new and modified inorganic sorbents, Amsterdam, 1996.pp. 115-146.

4. Gunko V.M., Matkovsky A.K., Charmas B. et al., J. of Thermal Analysis and Calorimetry, 2017, Vol. 128, Issue 3, pp. 1683-1697.

5. Patent of USA US9073038B2. Carr P.W., McCormick A.V., Paek Ch. Carbon coated silica particles and methods of making same. Publ. 07.07.2015.

6. Leboda R., Charmas B., SkubiszewskaZieba J. et al., Journal of Colloid and Interface Science, 2005, Vol. 284, Issue 1, pp. 39-47.

Нистратов Алексей Викторович, к.т.н., доцент РХТУ им. Д.И. Менделеева, Москва

Скарюкин Алексей Сергеевич, магистрант РХТУ им. Д.И. Менделеева, Москва

Клушин Виталий Николаевич, д.т.н., профессор РХТУ им. Д.И. Менделеева, Москва
7. Horikawa T., Hayashi J., Muroyama K., Carbon, 2002, Vol. 40, pp. 709-714. (Studies in Surface Science and Catalysis. Vol. 99).

8. Takamoto D.Y., Petrich M.A., Industrial \& Engineering Chemistry Research. 1994, Vol. 33, pp. 3004-3009.

9. Skarjukin A.S., Nistratov A.V., Klushin V.N., Kalinina D.D., Uspekhi $v$ khimii $i$ khimicheskoy tekhnologii. Moscow: Publ. of MUCTR, 2017, Vol. 31, No 9, pp. 47-49.

10. Alehina M.B. Promyshlennye adsorbenty: ucheb. Posobie, M., Publ. of MUCTR, 2007, $116 \mathrm{p}$.

11. Vjacheslavov A.S., Efremova M. Opredelenie ploshhadi poverhnosti i poristosti materialov metodom sorbcii gazov. Moscow: MSU of M.V. Lomonosov, 2011. 65 p.

12. Kolyshkin D.A., Mikhaylova K.K., Aktivnie ugli: svoystva i metody ispytaniy. Leningrad, Khimiya, 1972, 56 p.

Nistratov Alexey Viktorovich, Ph.D., associate professor of the Mendeleev University, Moscow, email: alvinist@yandex.ru

Skaryukin Alexey Sergeevich, master student of the Mendeleev University, Moscow

Klushin Vitaly Nikolaevich, Doctor of technical sciences, professor of the of the Mendeleev University, Moscow 